\title{
Paradigms and Scope of Engineering Technology Education
}

\author{
C. Richard G. Helps \\ Brigham Young University
}

\begin{abstract}
The scope of thinking skills required of Engineering Technology graduates is not often fully appreciated. Engineering Technology is frequently defined by critics and practitioners alike in terms of its pragmatic approach to education. Phrases such as "hands-on" "application-oriented" and "implementation-focused" are widely used. While this aspect is an essential component of Engineering Technology, it falls far short of the critical thinking skills and breadth of understanding and performance needed for a competent professional four-year engineering technologist. Merely identifying Engineering Technology in terms of an experiential approach to problem solving provides no useful paradigm to distinguish amongst craftsmen, technicians, four-year technologists or even engineers. Focusing only on the "hands-on" aspects of Engineering Technology can also lead to minimizing important topics of theoretical understanding, professionalism, communication and breadth of vision, among others.

Different models of the scope of engineering technology education exist. This paper describes a modified form of the "Knowing, Thinking, Doing" model and then describes a new model called the "Vision, Structure, Detail" model. The two models are complementary rather than competitive. Each has different strengths and limitations. Each emphasizes different aspects of technology education. The "Vision, Structure, Detail" model helps to emphasize creativity, communication and leadership aspects.
\end{abstract}

From the two models a more complete description of the thinking skills necessary to define fouryear Engineering Technology programs is developed. This gives insight into Engineering Technology education and the goals we need to develop and strive for as Engineering Technology educators. When applied together these two educational models lead towards a much clearer and grander vision of Engineering Technology education.

\section{Introduction}

Engineering Technology (ET) is often characterized by its application orientation. This is certainly one of its outstanding and essential characteristics but is far short of the potential that four-year ET students can achieve. Similarly, characterizing technology students as being "less math oriented than engineering students" also sadly misrepresents their abilities. Both of these characterizations have some validity but fall far short of accurately expressing the thinking and learning paradigms of ET. The potential of ET graduates is frequently underrated, sometimes even by those who are involved in teaching them. It is essential that ET faculty and administrators avoid falling into the trap of believing that ET students are just second-best 
engineers. A competent ET graduate has mastered a broad range of skills and attitudes and has both breadth and depth of understanding and experience in several areas. Properly structured ET educational curricula will recognize and develop the potential of the ET vision.

There are various models and descriptions of what is and what should be included in a technology education. One of these is the Know/Think/Do model ${ }^{1}$. This model was developed for secondary school technical education but adapts well to university level Engineering Technology. It encompasses the realms of activity necessary for a successful ET graduate and can be the basis for developing successful ET programs. There is great potential for ET graduates to be leaders and integrators in applying technology. A second model of ET educational activity, called the Vision/Structure/Detail model helps to realize this potential.

Both models are described and discussed in the paper and their application to ET education is discussed.

\section{The Knowing, Thinking, Doing (KTD) Model}

Knowing: "The mind is not a pail to be filled but a fire to be ignited." Emerson

Technology is a particularly challenging educational arena. Emerging technologies compete for class time with foundation classes, university general education classes and current technology classes. We want our students to be conversant with the latest technology and recognize that they need a scientific and engineering foundation, as well as other aspects of a complete university education, in order to be prepared for careers that include life-long learning. This breadth of knowledge will enable them to master new technologies throughout their professional lives and their knowledge of current technology will prepare them to function as competent professionals upon graduation.

It is necessary to have a deep knowledge of technology within their chosen field of study as well as a broad general knowledge. The technical knowledge should encompass key developments in the field with a clear understanding of why each development has changed technology and where it is likely to lead in the future. All the segments of the discipline must be linked and related into a coherent, rational whole. Only with such knowledge can model ET professionals build a worldview that will allow them to thoroughly understand their chosen field and, from that basis, develop new technology systems.

On the other hand we all face pressures to keep the total number of credit hours in a degree program down so that students can graduate timeously. Our goal in this area is that at the end of a four-year program students will have a profound knowledge of the state of technology based on a foundation of science, engineering and general education.

\section{Thinking:}

Knowledge must be allied with thinking skills. Students must become independent thinkers. ET graduates need to be able to think logically, critically, creatively and introspectively. Problem solving and decision-making are also key attributes of ETs. Problem solving cannot be achieved by a "cook book" approach. A "cook book" approach requires that someone else has anticipated all the problems that might arise and developed solutions for each of them in all possible combinations. To limit ETs to this type of design is surely a minimalist view of the scope of ET. 
Indeed, it is the very nature of ET to create fresh solutions to problems and to generate new applications for technology.

There is a progression of the quality of knowledge used in information processing that serves as a useful metaphor. The progression of data is from Data to Information, to Knowledge, to Understanding, to Wisdom. Of course, most computer systems only attempt to deal with the first three steps of this chain. The mechanism that takes one up this ladder of progression is the ability to think. While few programs aspire to achieve wisdom in their graduates we would all like our students to graduate with a deep understanding of technology and all its processes.

Doing: "In theory there is no difference between theory and practice. In practice there is" author unknown

One of the hallmarks of ET education is its application orientation. It is well known that some people learn experientially ${ }^{4}$. Implementation of concepts brings together knowledge and theoretical understanding ${ }^{2}$. This is one of the strengths of ET. Another aspect of experiential learning in an ET context is that upon graduation students not only have a grasp of the theoretical underpinning of their field, they also have the ability to integrate their knowledge and understanding of technology to build complex technological solutions to problems.

The KTD model is a good summary of the activities that we want our students involved in. It helps to balance our efforts as we develop curricula and as we teach. There are many other desirable traits which can be included in the KTD model but which are not specifically emphasized by it. In ET we emphasize the importance of communication, oral and written; our graduates are also actively involved in creative design work and many of them go on to assume leadership roles in their future careers. As we have developed new curricula at BYU we have also developed a new model to complement the KTD model. This model is referred to as the Vision/Structure/Detail model.

\section{The Vision, Structure, Detail (VSD) Model}

The VSD model of technical activities illuminates the discussion in a different way. This proposes three approaches to problems, namely, Vision, Structure and Detail. This model was developed as part of a process of curriculum reform in a four-year technology program at BYU. It became necessary to differentiate between the different roles people fill within an organization and also the different roles technologists assume in different aspects of their work. The "Vision, Structure, Detail" model revealed strengths and weaknesses of existing and proposed curricular directions. This model can generally be applied to many situations but it is particularly suitable for engineering technology enterprises. The model is as follows.

Vision: "Where there is no vision the people perish" Proverbs 29:18

An overarching vision is essential to the success of a major enterprise. CEOs, presidents and indeed, all great leaders are visionary to some extent. While not all those involved in the enterprise necessarily have the global visionary viewpoint, all should be able to recognize it and develop personal visions to contribute to the dynamically changing overall vision of the enterprise. ${ }^{3}$ Having a personal vision as part of the overall vision can inspire participants to great commitment and sacrifice, to achieve beyond their expectations and hopes. 
Within the scope of an individual or team endeavor, all professionals should aspire to and achieve a vision of their own realm of activity. Furthermore, communication of that vision is essential for anyone pursuing a project involving more than one person. This is perhaps the most important underlying reason for us to emphasize communication in ET. If professional ETs have a clear understanding of how a complex technical task needs to be completed, they need to understand how it fits into the overall vision of the enterprise and then be able to communicate their own vision of their own task to others so that it can become part of the overall effort. For example, an engineering technologist may be the only one who understands why a particular, very expensive, piece of test equipment needs to be purchased. She needs to understand how that will affect the overall goals of the company and then communicate the need to those who will authorize the expenditure and who, most probably, lack the technical background or specialized knowledge that the technologist has.

Creativity demands vision. To successfully design a technical solution to a problem, an understanding of the problem must be coupled with a concept, a vision, of the solution. This vision must encompass both the local vision of a creative technical solution as well as a global vision of the enterprise. Once the local vision is formed design efforts are then focused on fulfilling that vision. If the solution is relatively complex a structure will also be required to direct the efforts.

\section{Structure:}

For a vision to be realized its structure needs to be defined. Structured thinking is one of the major objectives of modern technical university education. Students in engineering and technology are taught to think scientifically and critically. Cause and effect relationships are emphasized, as is the necessity for a modular approach to problem solving. Step by step design methodologies and problem solving techniques are taught along with mathematical thinking. This approach encourages practitioners to analyze problems in the simplest possible terms so that rational solutions can be achieved in a finite time. An excellent example of structured thinking is embodied in the process of technical project management. Needs and expectations are calculated. Time, materials, people and other resources are carefully allocated to each stage of the project. The project is broken down into several phases and each major phase is further subdivided into monthly, weekly and daily goals. Creative and standardized techniques are developed to handle inevitable variations in the project.

Creation of structure alone does not complete the task. There is a significant amount of detailed work that needs to be done.

\section{Detail: "The devil is in the details" author unknown}

The detailed work is where the vision finally comes into reality. This is a very rewarding part of the whole creative process. The details are not just fluid creative options but are strongly constrained by the chosen structural elements. In an electronic circuit every component must be correctly chosen and correctly matched to other components, and the circuit must be constructed with great care and reliability; otherwise the system won't function at all or will function very poorly.

Many technical people are happy working in this detailed environment, feeling that this is where the "real work" is done. This is where we find programmers who love to code, engineers who 
love to be in the workshop and craftsmen lovingly completing every detail of their job. This is the base of the pyramid. None of the vision and structure can bear fruit without the detailed work. On the other hand no complex project can be completed without the structure and vision either. An example of the relationship between structure and details is demonstrated in the way computer programmers build software structures that many programmers can contribute to, structures which are maintainable and reliable. Using this structured software approach programs of millions of lines of code can be developed by groups of individuals and individualistic programmers that all successfully cooperate together in their detailed tasks.

Even though certain people tend to function best in certain roles, at times it is necessary for technologists to assume all of the different roles of the VSD model. For the successful implementation of systems, attention to detail is essential. Structure is equally important in design, and ETs are typically involved in all stages of design. Finally, as we expect our ETs to progress into leadership roles within their profession and within the professional community, it is necessary that they be able to visualize complete systems in the context of the world in which they will operate. It is becoming increasingly necessary for ETs to be cognizant of broader issues such as user needs, environmental concerns, legal issues and business opportunities as they pursue their profession. Thus successful ETs must be competent at all three levels of this model.

\section{Application of the models to the profession}

Technologists are occasionally accused of being very narrow in their education. The suggestion is that technologists are trained, not educated, that they are simply taught a set of skills rather than being taught to think, reason and understand. It is further suggested that not only is the education of ET students narrow in scope and strictly job-oriented but that their focus is even narrower than that of engineers, a notoriously tightly focused group, and that technologists lack even the math skills which engineers have as evidence of rational thinking. If this is an accurate description of any current ET program then it is indeed a severe indictment. Any ET educator who feels that his role is to offer an educational opportunity for those who cannot succeed mathematically and can learn only through "hands-on" would do well to consider the limitations of such a vision. I would contend, however, that the thinking required of successful ETs is very challenging. Not only must they be able to think rationally but also creatively to a marked degree. In tackling the problems of bringing technology to life in the "real world" a successful technologist must be able to develop an idea and then follow that idea with flawless logic and dogged perseverance all the way to its practical conclusion. Only thus can an idea be successfully brought into reality.

Those who work more in the realms of ideas and human communication, such as sales people, psychologists and business leaders, use great flexibility in their communications; they change their arguments and approach to suit the changing needs and emotions of the situation. A tense confrontation can be converted into a personal triumph by one skilled in understanding human moods and communications, and willing to change the nature of the discussion and perhaps even the facts to suit the current situation. Similarly a creative artist can see beauty where others can see only ugliness. By using talents and skills a good artist can re-interpret the ugliness so that the beauty is revealed.

This freedom of interpretation is not available to the technologist. The inexorable logic and laws of technology are extremely unforgiving. If the design and implementation are not correct in every detail then the system will not function properly, and its failures will probably be evident 
to experts and lay people alike. Indeed, the thinking discipline of the technologist must go beyond that of the theoretical designer who works with a sophisticated simulation and design tool which models the environment in which the design is to operate. Such a simulated environment obeys a strict set of rules known to the designer of the simulator and these rules are hopefully closely reflective of the system being simulated. Design rules in such environments will always work, for they are specifically designed to meet the needs of the known, simulated environment.

The technologist, on the other hand, is required to make a design work in the real world, the operation of which is only partially described by the known laws of physics, chemistry and other sciences. While knowledge of the sciences combined with mathematical skills is essential to understand the approximate nature of the problem, it is frequently insufficient to solve all the problems encountered. A good technologist must be able to remorselessly follow a logical train of thought, observing real effects and including them in the reasoning chain. It requires significant discipline to acquire the scientific and reasoning skills necessary to make sense out of a chaotic world. It requires an even higher level of thought to be willing to accept the evidence displayed by a system which seems to contradict known laws: to accept as the ultimate reference the actual outcome of a test and relentlessly follow the chain of thought these results engender. Incompletely understood physical laws may need to be bypassed until one reaches a point of understanding where either the physical laws are seen to, in fact, explain the observed phenomena, or a solution is generated which is proved to work reliably in all relevant circumstances despite the fact that the operation cannot be adequately described by known science.

One also needs to use creativity and vision to avoid the intellectual trap of being paralyzed by too much knowledge: that is, knowing enough theories that one continually strives to apply the laws and equations to the observed phenomena but never actually manages to solve the problem.

\section{Application of the models to Engineering Technology Education}

These models, applied together, can help us develop excellent ET curricula. While ET education should always encompass all aspects of "Knowing, Thinking, Doing," the VSD model represents more of a scale on which people operate at different times. It is the author's opinion that most four-year ET programs are focused primarily on detail and somewhat on structure, but do not emphasize vision. Engineering programs are traditionally strong in structure and adequate in detail but are also traditionally not strong in vision. Thus one of the common criticisms leveled at engineering is that they are focused on the technology details and ignore the "real world". To the extent that this is true it is a weakness in these programs.

Both of these models are necessary. The first is used as a guideline in ensuring that all necessary aspects of ET education are carried out. Theory without practice is as bad as practice without theory and either without thinking is weak. Similarly, the second model is used to ensure that the scope of ET education is properly considered. If, for example, there is insufficient detail in courses students will not become practitioners of the art; the best they can hope for will be to become enthusiastic spectators, and without vision they will be just technical drones executing, however excellently, the ideas of others. Finally, structure is also essential. No complex technical project can be completed without an appropriate structure being defined. 
These models should be used as yardsticks in curriculum development. For every course the questions should be asked, "What are the thinking, knowing and doing aspects of the course?" and also, "Where are the vision, structure and detail emphases in the course?" These models coexist within ET education space but are somewhat independent of each other. For example, thinking should be applied to all aspects of vision, structure and detail. Similarly, structure should be present in aspects of thinking, knowing and doing in that each of these should have a clear structure or plan.

\section{Conclusion}

When applied together these two educational models lead towards a much clearer and grander vision of Engineering Technology education. ET graduates can become leaders with a profound technical knowledge and understanding, competent to manage complex projects creating and building new technical applications that work down to the last detail.

Bibliography

1. Johnson, S.D., and Erekson, T. L. Technology's role in vocational education reform Illinois Vocational Educational Journal. 44, 1, 11-15

2. Grinter, Linton E., Summary of the Report on Evaluation of Engineering Education. Published in the Journal of Engineering Education, Sept 1955 pp 25-60. This reference reprinted in Journal of Engineering Education, January 1994, pp 74-94, pp79, 82 referenced in text. Article available from http://www.asee.org/publications/reports/grinter.cfm.

3. Senge, P. The Fifth discipline, new York, Doubleday, (1990), p211

4. Lunt, Barry M., Predicting academic success in electronics 1993. Thesis (Ph.D.) Utah State University. Dept. of Education

\section{RICHARD G. HELPS}

Richard Helps is the Program Chair of the Electronics Engineering Technology program at BYU. He is also a TACABET program evaluator and vice-chair of the ECET Department Heads Association. He spent ten years in industry as a control systems design engineer. He completed BS and MS degrees at the U of the Witwatersrand, South Africa and a further graduate degree in Electrical Engineering at the University of Utah. His primary interests are in embedded and real-time computing with its instrumentation and control aspects, combined with artificial intelligence techniques such as neural networks and fuzzy logic. 